\title{
Exploring Teachers' Views on the Impact of an Online Distance Learning Course on Their Self-Efficacy Beliefs
}

\author{
Eirini Tzovla (Corresponding author) \\ Department of Molecular Biology \& Genetics, Democritus University of Thrace, Greece \\ E-mail: etzovla@mbg.duth.gr \\ Katerina Kedraka \\ Department of Molecular Biology \& Genetics, Democritus University of Thrace, Greece \\ E-mail: kkedraka@mbg.duth.gr
}

Received: April 26, 2021 Accepted: August 31, $2021 \quad$ Published: September 3, 2021

doi:10.5296/ijld.v11i3.18563 URL: https://doi.org/10.5296/ijld.v11i3.18563

\begin{abstract}
This paper reports on an online distance learning course that emphasizes the improvement of the self-efficacy beliefs of in-service elementary school teachers in teaching biological concepts. The course utilizes digital educational content and Open Educational Resources (OERs) and focuses on the interaction, peer support, and peer teaching into an online learning environment. In the design framework of the course, we investigated the educational needs of teachers and took into consideration the findings of other studies. A total of 251 teachers were enrolled in the online distance learning course and 142 completed it. Quantitative and qualitative data was collected in November 2020 through the bio-STEBI-A instrument and the posts in the forums of the course. The quantitative results revealed an improvement in both subscales of bio-STEBI-A, which were also confirmed by the qualitative ones, that underline the course, thus contributing to the improvement of self-efficacy beliefs of in-service elementary school teachers in teaching biological concepts. Recommendations are made for future research.
\end{abstract}

Keywords: online distance learning courses, biological concepts, in-service elementary school teachers, self-efficacy beliefs 


\section{Introduction}

Effective teaching is a great challenge for all subjects and all levels of education and is directly related to the teachers' self-efficacy beliefs, which affect their teaching behavior, their teaching practices, and the learning outcomes (Bandura, 1997). Studies indicate that teachers' self-efficacy beliefs influence students' attitudes towards school (Bergman \& Morphew, 2015) and their self-efficacy (Bandura, 2006) and put emphasis on the need to strengthen them (Kazempour \& Amirshokoohi, 2013). The improvement of self-efficacy beliefs could come from targeted teacher professional development courses (Ravandpour, 2019), which contribute to the updating of knowledge and skills, the adoption of new teaching practices, the improvement of learning outcomes, and ultimately in changing teachers' attitudes and beliefs about teaching (Guskey, 2002).

Studies report improvement of teachers' self-efficacy they participate in professional development courses (Mulholland et al., 2004; Kreischer-Gajewicz, 2019), which over the last decade have increasingly been offered in the form of online distance learning courses (Aji \& Khan, 2019; Mertasari \& Candiasa, 2020; Yoo, 2016). These courses are facilitated by the digital revolution and enhance opportunities to teachers for utilization of technology platforms, mobile devices, social media, and access to digital educational content and OERs.

\section{Literature Review}

Self-efficacy refers to the way a person perceives oneself, interprets the facts, and decides upon the motivations and expectations, which determine one's behavior (Bandura, 1997). Bandura analyzes the self-efficacy beliefs in personal self-efficacy and outcome expectancy beliefs. Similarly, to the general self-efficacy beliefs, exist the Science self-efficacy beliefs, which relate to the beliefs in personal abilities to teach Science effectively (Personal Science Teaching Efficacy, PSTE) and the beliefs that Science effective teaching can positively affect learning outcomes (Science Teaching Outcome Expectancy, STOE) (Riggs \& Enochs, 1990).

Menon and Sadler (2017) report that low self-efficacy beliefs are a barrier to effective Science teaching and Avery and Meyer (2012) and Bergman and Morphew (2015) argue that low Science self-efficacy beliefs are related to the choice of inadequate teaching practices. Moreover, other researchers (Harding, 2016; Mintzes, et al., 2013; Schneider, 2020) note that online learning environments could play an important role in changing teachers' Science self-efficacy beliefs, and Baran and Alzoubi (2020), and Gosselin et al. (2010), highlight the significant role of online learning communities in active learning and interaction among participants. Additionally, Blank et al. (2008) indicate that professional development courses should be related to curriculum, and Fulton et al. (2010) reviewing fifty STEM-related papers, found that learning within professional communities involves teachers in comprehensive discussions about Science while improving their preparation for the Science teaching and their attitudes towards it.

Moreover, the majority of the studies regarding face-to-face professional development Science courses report an improvement in participants' self-efficacy (Hankel, 2019; Kang et al., 2019; Schneider, 2020; Velthuis et al., 2014). The few studies that have been conducted to 
investigate teachers' self-efficacy in teaching biological concepts note an improvement mainly in the personal self-efficacy beliefs of both pre-service teachers, who have attended live courses for biological concepts (Al Sultan et al., 2018; Avery \& Meyer, 2012; Savran \& Çakiroğlu, 2001) as well as in-service teachers who participated in live professional development courses (Elster, 2012; Haney et al., 2007; Peters-Burton et al., 2015). However, the literature review does not indicate online professional development courses that focus on enhancing the self-efficacy of in-service elementary teachers. This paper, therefore, attempts to contribute to the field.

\section{Research Objectives}

The fact that very few extensive studies to investigate the self-efficacy beliefs of teachers in teaching biological concepts have been conducted, the importance of teachers enhanced self-efficacy beliefs for effective teaching, the need to cultivate biological literacy from the first levels of education due to the recent pandemic Covid 19 (Tzovla \& Kedraka, 2020a) and the interest and the need that a significant number of in-service elementary school teachers expressed prompted us to design and implement an online distance learning course utilizing digital educational content and OERs. Our study aims to investigate the contribution of this course to improve the self-efficacy beliefs of in-service elementary school teachers who teach biological concepts in Primary Schools through their participation in an online learning environment.

Subsequently, we present the design and implementation of the course and the participants' views about its contribution to reinforcing teachers' self-efficacy beliefs.

\section{Design and Implementation of an Online Distance Learning Course Regarding the Teaching of Biological Concepts in Primary School}

In May 2020, we surveyed a significant sample $(\mathrm{N}=509)$ of Greek in-service elementary school teachers to investigate their self-efficacy beliefs in teaching biological concepts (Authors, 2020). For data collection we used the bio-STEBI-A instrument (Appendix), which consisted of two subscales and investigated a) Personal Biology Teaching Efficacy Belief (PBTE) (13 items) and b) Biology Teaching Outcome Expectancy (BTOE) (11 items) and was an adaptation of the instrument STEBI-A by Riggs and Enochs (1990). Cronbach's Alpha (above or very close to 0.8 ) in both subscales indicates that the measurements showed satisfactory reliability (Field, 2009). Moreover, it has adequate validity as it has been used for measurement in-service teachers' self-efficacy beliefs in biological concepts (Angle \& Moseley, 2009; Haney et al., 2007). The findings advocated that the participants had moderate self-efficacy beliefs (Tzovla \& Kedraka, 2020b). This result led us to search for a teacher professional development scheme that could improve their self-efficacy beliefs. The instructional design model we relied on to develop our course was the hybrid design scheme of MOOC initially proposed by Koukis and Jimoyiannis $(2017,2019)$ and it has been implemented in Greek secondary language teachers. Following the above scheme, the course had a specific structure, content, and evaluation and was based on teachers' active participation and peer-supported learning. We have configured the above scheme to improve the self-efficacy beliefs of teachers who teach biological concepts in Primary School. 
Our course utilizes digital educational content and OERs, enhances active learning, the interaction, and the sharing of digital educational resources, knowledge, and practices and asks the participants to create educational activities for teaching biological concepts within an online learning community. Specifically, after an invitation to the in-service elementary school teachers, who filled in the bio-STEBI-A questionnaire, we explored their interest in participating in an online course that utilizes digital educational content and OERs in the teaching of biological concepts in Primary School and 349 of them expressed interest in attending it (Tzovla et al., 2021a). In the design framework of the course, we included a questionnaire, which investigated their educational needs (Oh et al., 2019) and took into consideration the harnessing findings of studies that investigate the dropout from online courses (Gamage et al., 2016; Qian et al., 2018). Finally, we created a course, which based on the results of the investigation of the educational needs of the participants. The fundamental design principles were self-regulated learning, the autonomy of the participants, and peer-supported learning (Moreno-Marcos et al., 2020).

The course was entitled "Teaching biological concepts in Primary Education using Digital Educational Content and Open Educational Resources", implemented from September $28^{\text {th }}$ to November $1^{\text {st }}, 2020$, was organized in 5 modules, was asynchronous, and was hosted by the familiar to most Greek in-service elementary school teachers Open e-Class 3 e-learning platform. Each course unit included basic and supplementary educational material related to teaching biological concepts in Primary School, appropriate presentations (ppt) and videos about the course's basic concepts, self-assessment tests, the weekly obligations of the participants, and discussion forums. The participants were encouraged to utilize the digital educational content and OERs which are offered by the course, design activities for the teaching of biological concepts, enrich them with digital educational content and OERs proposed by the participants through peer support, and reflect on their implementation. This principle has proved effective, as an impressive volume of digital educational content and OERs was posted by the participants themselves and a wide range of educational interventions for the teaching of biological concepts in Primary Education was designed and implemented.

Upon completion of the course, participants were asked to fill in the bio-STEBI-A again (Tzovla et al., 2021b). Quantitative data advocated that participants' self-efficacy beliefs in teaching biological concepts improved after they participated in it. At the same time, during the $5^{\text {th }}$ week of the course, the participants were asked to comment on their participation in the course and its contribution to the improvement of their self-efficacy beliefs. Relevant forum threads were opened on the platform.

\section{Method}

\subsection{Data Collection and Procedure}

To draw safer conclusions for the impact of the course on participants' self-efficacy beliefs, data was gathered from forum postings and was evaluated additionally to the analysis of quantitative. The procedure took place mainly during the forum of the $5^{\text {th }}$ week and it concerned: a) the overall contribution of the online distance learning course to enhancing 
self-efficacy beliefs, b) the contribution of it to improving participants' PBTE and, c) its contribution to improving participants' BTOE. The data collection started on November $1^{\text {st }}$, 2020, and lasted until November $8^{\text {th }}$, 2020. In decoding the posts, we used the content analysis method (Bryman, 2016) and proceeded to codify the comments, identify categories and present the findings.

\subsection{The Sample}

The sample consisted of 127 teachers, who had completed the bio-STEBI-A in the initial study in May 2020, attended the course, completed their activities and filled in the bio-STEBI-A again after the completion of the course in November 2020. The majority of them were women $(82,7 \%)$, over 31 years old $(52,8 \%)$, had attended the Humanities orientation group of the Last Grade in Lyceum (56,7\%), they had no postgraduate studies $(63 \%)$ and had taught in all grades of Primary Education $(58,1 \%)$. Most of them worked in Primary Schools in Attica, Greece, they were volunteers and had expressed interest in attending the course. Table 1 shows the demographic characteristics of participants.

Table 1. Participants' demographic characteristics $(\mathrm{N}=127)$

\begin{tabular}{lll}
\hline \multirow{2}{*}{ Gender } & Male & $17.3 \%$ \\
& Female & $82.7 \%$ \\
\hline \multirow{3}{*}{ Age } & $<=30$ & $16.5 \%$ \\
& $31-40$ & $26.8 \%$ \\
& $41-50$ & $26.0 \%$ \\
& $>=51$ & $30.7 \%$ \\
Orientation Group of the Last & Sciences & $22.0 \%$ \\
& Economic \& Computer & $21.3 \%$ \\
& Humanities & $56.7 \%$ \\
\hline \multirow{2}{*}{ Teaching experience (years) } & $<=5$ & $16.5 \%$ \\
& $6-10$ & $7.9 \%$ \\
& $11-20$ & $43.3 \%$ \\
Postgraduate studies & $>=21$ & $32.3 \%$ \\
\hline \multirow{2}{*}{ Teaching Grade } & Yes & $37.0 \%$ \\
& No & $63.0 \%$ \\
\hline & First - Second & $7.0 \%$ \\
& Third - Fourth & $4.7 \%$ \\
& Fifth - Sixth & $30.2 \%$ \\
& Combination & $58.1 \%$ \\
\hline
\end{tabular}




\section{Results}

The participation of the teachers in the forums of all 5-course units was remarkable. Specifically, 83 discussion topics were raised from the participants, in which 1530 posts were uploaded and 8.211 visits were recorded. The vast majority of the posts were positive to the course and its contribution to their self-efficacy beliefs. Likewise, the posts emphasized the importance of teaching biological concepts in Primary Education and the use of digital educational content and OERs.

The final week, the discussion focused on active engagement, interaction, mutual support, sharing of knowledge, practices, activities and, experiences. These group discussions contributed to the creation of an online learning community that enhanced participants' self-efficacy and the course reinforced their PBTE and BTOE.

Of the 349 teachers who had expressed interest in attending the course, 251 of them finally enrolled 142 completed it (56.57\%), and 127 filled in the bio-STEBI-A. The quantitative results advocated that the teachers, who participated in the course seem to have higher scores in both subscales (PBTE and BTOE) compared to the teachers of the group who did not participate in the course (Tzovla et al., 2021b). In addition, these results were also confirmed by the qualitative ones, as views were expressed, which are in line with the statements of the bio-STEBI-A for which revealed statistically significant differences.

6.1 Teachers' views about the contribution of the online distance learning course in their self-efficacy

The posts in the forum advocated that the course contributed significantly to boosting their self-efficacy beliefs in teaching biological concepts. Specifically, it was highlighted that peer teaching, support, and interaction, which were used within the learning community, related positively to the improvement of participants' self-efficacy beliefs.

The following transcripts highlight the contribution of the above in enhancing teachers' self-efficacy (M: Message):

M1367 "Interaction with colleagues, the theoretical part of the course, the educational digital material, and the targeted comments/remarks in the forums, were very supportive, enriched our teaching interventions for biological concepts, and gave new ideas for action in the classroom! This has led us to believe that we can effectively teach biological concepts..."

M1308 "...By creating activities with the support of the community we found out that collaboration makes us more effective in our teaching..."

Regarding the significance of sharing ideas, practices, activities, and experiences in the improvement of self-efficacy beliefs, the following comments are representative of many similarities:

M1321 "...The best part of the course was the opportunity we all had to share ideas, activities, and practices with colleagues, to exchange views and experiences, which we incorporated in our educational interventions ... which made us feel safer when we implemented our activities to the classroom " 
M1328 “...A learning community was created where participants sharing views, ideas, and practices interacted with each other. One complemented each other and finally, we made interesting and feasible teaching proposals, applicable in the classroom ... So, we felt more confident about what we taught and our students were excited about what they learned..."

The comments concerning the organization and structure of the course are worth mentioning:

M1340 "...Extremely interesting course, fully targeted, well-structured and effective ... offered us the theoretical and practical framework we needed to be able to teach biological concepts effectively..."

M1348 "...Very important parameters of the course were the detailed presentation of the modules and the grouping of the educational material, a fact that helped our actions and strengthened us in our teaching. After course attendance, I approach the teaching of biological concepts differently and I feel that I can teach them effectively..."

Worth noting are the posts on the constant feedback and support from the educators:

M1353 "...I must point out the supportive attitude of the educators, who constantly reinforced us with constructive feedback, which strengthened our belief that we can teach biological concepts effectively and have positive learning outcomes..."

M1359 "...The constant feedback and encouragement from the educators contributed significantly to me completing the course and to believe that I am an effective teacher!"

6.2 Teachers' views about the contribution of the online distance learning course in their Personal Biology Teaching Efficacy

Regarding the contribution of the course to the PBTE of the participants $\left(1^{\text {st }}\right.$ subscale of bio-STEBI-A) posts that uploaded are following the statements of the PBTE revealed statistically significant differences and support the findings of the quantitative data.

Participants note that the course contributed to:

- The most effective teaching of biological concepts (items 2, 5, 8 of bio-STEBI-A):

M1387 "...After the course, I have more confidence to teach biological concepts by utilizing digital educational content and OERs, because what I learned helped me to enrich my teaching..."

M1432 "The course was very useful for my teaching... and further enhanced my effectiveness... and I certainly feel more capable and effective in teaching biological concepts..."

- The knowledge of biological concepts (items 12 of bio-STEBI-A):

M1382 “...The course contributed effectively to the knowledge of biological concepts that are part of Science teaching in Primary School...to get familiar with the digital educational content and OERs, to search them and to integrate them in my teaching. In this perspective, I think that I can effectively teach biological concepts in Primary Education..." 


\section{Macrothink}

M1431 "...To be more effective in teaching biological concepts in elementary school because I know them better...I observed better results by implementing the activities in the classroom because children understood " difficult" biological concepts..."

- Ability of teachers to answer their students' questions about biological concepts (items 18 , 22,23 of bio-STEBI-A):

M1400 "...we can answer children's questions with more confidence, believing that we can effectively teach biological concepts in Primary Education..."

M1452 "... now I feel safer when I teach biological concepts, confident that I can answer my students' questions and choose material to stimulate their interest..."

- Enhance students' interest in biological concepts (item 24 of bio-STEBI-A):

M1443 "... it helped me improve myself and make my teaching more exciting for my students..."

M1453"...my participation in this course helped me to search and integrate OERs in the teaching of biological concepts to stimulate the interest of students and to ensure their involvement in a dynamic way..."

- Utilization of digital educational content and OERs in monitoring biological experiments (items 6,17 of bio-STEBI-A):

M1387 "...digital resources, visualization, and simulation help to understand biological concepts, which are often very abstract for children..."

M1404 "...in teaching biological concepts, content such as simulations and visualizations succeed in presenting them vividly and experientially ..."

6.3 Teachers'views about the contribution of the online distance learning course in their Biology Teaching Outcome Expectancy

As far as the BTOE ( $2^{\text {nd }}$ sub-scale of the bio-STEBI-A) qualitative data analysis confirms the quantitative ones and is in accordance with the statements of BTOE that revealed statistically significant differences. Specifically, the participants claimed that:

- The effort made by the teacher influences the learning outcomes in the teaching of biological concepts (items 1, 11, 15 of bio-STEBI-A):

M1457 "...the role of the teachers in learning outcomes is catalytic; the effort they make can affect the background of the students and contributes substantially to the improvement of their performance..."

M1502 "...I believe that a well-designed and organized teaching intervention can help students understand biological concepts..."

- An effective ways of teaching method improves the grade of students regarding biological concepts (item 4 of bio-STEBI-A):

M1487 "...the utilization of the digital resources will bring better results in the teaching of biological concepts..."

M1488 “...we as teachers should look for ways of teaching, different from the 


\section{Macrothink}

traditional ones, to improve the grade of students and enhance the love for the biological concepts. The methods we use are related to the effectiveness of our teaching..."

- Effectiveness in biological concepts teaching influences students with inadequate background (item 9 of bio-STEBI-A):

M1499 "...we must do our bests, to" drag" all the students especially the "weakest" student along the journey of knowledge..."

M1506 "...digital resources attract students with low background and boost their self-efficacy, make them more actively involved and help them to understand the biological concepts..."

- The low achievement in biological concepts of some students cannot generally be blamed on their teachers (item 10 of bio-STEBI-A):

M1511 "...the performance and learning outcomes of our students are not influenced solely by us!"

M1529 "...the achievements of our students depend on their abilities, their personality, their cognitive environment, as well as on how well prepared and equipped the teacher is..."

- Students' achievements of biological concepts are related to teacher effectiveness and effort (item 25 of bio-STEBI-A):

M1485 "...the effectiveness of the teacher, the effort he makes can affect the students' achievements and contribute substantially to improving their performance..."

M1517 "...therefore the teacher has the responsibility for choosing the adequate methods and practices for the teaching of biological concept... to improve the learning outcomes..."

\section{Discussion}

The quantitative analysis of our course revealed an improvement in both PBTE and BTOE. These findings were also confirmed by the qualitative analysis of the study, as the participants' posts in the forum agree with the quantitative findings of the bio-STEBI-A (Tzovla et al., 2021b). About the PBTE, the views of the teachers who participated in the course support the statements of the questionnaire that the course contributed to the more effective teaching of biological concepts, improved knowledge of the biological concepts, enhanced the ability of teachers to answer their students' questions about biological concepts and students' interest for biological concepts, utilize digital educational content and OERs in the monitoring of experiments. Similarly, concerning BTOE the qualitative results and qualitative data provided supportive evidence to the quantitative ones, on the effort made by the teachers. It seems it is essential for the learning outcomes of students for the teaching of biological concepts since an effective teaching method improves the understanding of biological concepts, which in turn encourages students with an inadequate background. In 
addition, the participants note the effort that the teacher makes influences the learning outcomes, students' achievements in biological concepts are related to teacher effectiveness but teachers cannot generally be blamed for the student's achievements. The above findings are consistent with the findings of Aji and Khan (2019), Gosselin et al. (2010), Mertasari and Candiasa (2020), and Yoo (2016), who argue that the improvement of teachers' self-efficacy in other fields and highlight the potential of online courses as a model of professional development of teachers.

In addition, it appears that the features of sharing knowledge, activities, practices, and experiences, peer teaching, active engagement, interaction among participants, and mutual support within an online learning environment enhanced the opportunity for improvement of teachers' self-efficacy beliefs. These findings agree with the findings of Baran and Alzoubi (2020), Gosselin et al. (2010), who claim that the aforementioned topics motivate teachers to participate in professional development courses. Furthermore, the constant encouragement, support, and feedback with constructive comments from the educators reinforced participants' self-efficacy beliefs.

It is worth noting that a narrow range of studies found improvement of BTOE after participating in online courses including our study. It seems that our course met the participants' needs as the course emphasizes them as they expressed in the questionnaire and linked the course to the curriculum, a finding, which was also underlined as important by Blank et al. (2008), who link the effectiveness of professional development courses to their focus on curriculum. Other interesting findings are the high rate of completion as well as the feedback from the participants regarding the contribution of the course to effective learning. These findings revealed that the participants were satisfied with this online experience, which strengthens the adoption of professional development online distance learning courses as an effective educational tool for teachers' professional development.

Finally, our study revealed the growing interest in teaching biological concepts in Primary Education, the contribution of the utilization of digital educational content and OERs in this teaching and highlighted the online distance learning courses as a flexible, collaborative, and constructive form of professional development, which can contribute positively to the improvement of teachers' self-efficacy beliefs.

\section{Conclusion, Limitations, and Future Research}

Concluding, the analysis of the qualitative findings in our study led to the conclusion that the teachers were positive about a course in the form presented in this paper because it provides the framework to boost teachers' self-efficacy beliefs. The fact that our course aimed at the personalized learning and meet the needs of the participants as we had explored them is an element that seems to play an important role in the success of its aims.

The findings of the present study could be the basis for further research. It would be interesting to explore how professional development online distance learning courses can enhance the self-efficacy of teachers who teach not only other subjects in Primary School but also at other levels of education. Moreover, of special interest would be to explore the self-efficacy beliefs of pre-service elementary school teachers, to determine their readiness 
and self-efficacy beliefs before they come to teach biological concepts in Primary School, and to compare their self-efficacy beliefs with in-service elementary school teachers' beliefs. In addition, teachers who participated in our course could be observed in the classroom using appropriate protocols, interviewed about the course's contribution to their improvement of their self-efficacy, and combine this data with existing ones to extract conclusions. The above investigation could be combined with research on improving the learning outcomes of students whose teachers have attended this course. Another interesting line of research would be the further exploration of the role of online learning communities in enhancing teachers' self-efficacy beliefs.

Finally, considering the methods of our study, we recognize that the study had some limitations. The lack of previous research on measuring the self-efficacy beliefs of teachers in teaching biological concepts does not allow the comparison and confirmation of the present findings. Likewise, although we had a low rate of drop-out, among those who participated in the course, the present findings should be interpreted with caution to consider context-specific generalization as the participants were mainly from a specific region of the country, which may affect the results.

As online distance learning courses are a particularly effective form of teachers' professional development and given the Covid-19 pandemic, it would be of particular interest to further explore their effectiveness.

\section{References}

Aji, C., \& Khan, M. (2019). A Flight Simulator-Based Active Learning Environment. Open Journal of Social Sciences, 7, 192-203. https://doi.org/10.4236/jss.2019.73016

Al Sultan, A., Henson Jr. H., \& Fadde, P. J. (2018). Pre-Service Elementary Teachers' Scientific Literacy and Self-Efficacy in Teaching Science. IAFOR Journal of Education, 6(1). https://doi.org/10.22492/ije.6.1.02

Angle, J., \& Moseley, C. (2009). Science teacher efficacy and outcome expectancy as predictors of students' end-of-instruction (EOI) biology I test scores. School Science and Mathematics, 109(8), 473-483. https://doi.org/10.1111/j.1949-8594.2009.tb18294.x

Avery, L. M., \& Meyer, D. Z. (2012). Teaching science as science is practiced: Opportunities and limits for enhancing preservice elementary teachers' self-efficacy for science and science teaching. School Science and Mathematics, 112(7), 395-409. https://doi.org/10.1111/j.1949-8594.2012.00159.x

Bandura, A. (1997). Self-efficacy: The exercise of control. W H Freeman/Times Books/ Henry Holt \& Co.

Bandura, A. (2006). Guide for constructing self-efficacy scales. In F. Pajares \& T. Urdan (Eds.), Self-efficacy beliefs of adolescents (Vol. 5, pp. 307-337). Greenwich, CT: Information Age Publishing.

Baran, E., \& Alzoubi, D. (2020). Human-centered design as a frame for transition to remote teaching during the COVID-19 pandemic. Journal of Technology and Teacher Education, 
$28(2), 365-372$.

Bergman, D. J., \& Morphew, J. (2015). Effects of a science content course on elementary preservice teachers' self-efficacy of teaching science. Journal of College Science Teaching, 44(3), 73-81. https://doi.org/10.2505/4/jcst15_044_03_73

Blank, R. K., de las Alas, N., \& Smith, C. (2008). Does Teacher Professional Development Have Effects on Teaching and Learning?: Evaluation Findings from Pro-grams in 14 States. Washington, DC: Council of Chief State School Officers.

Bryman, A. (2016). Social research methods. UK: Oxford University Press.

Elster, D. (2012). Reform in biology education: teachers and researchers in a process of negotiation. In Daugbjerg, P. S. (Eds.), Proceedings of Science teachers' narratives on motivation and commitment: A story about recruitment and retention. Paper presented at European Science Education Research Association, Lyon, France. https://vbn.aau.dk/ws/files/78578296/ebook_esera2011_Strand13.pdf

Field, A. (2009). Discovering Statistics Using IBM SPSS Statistics (3rd ed.). SAGE.

Fulton, K., Doerr, H., \& Britton, T. (2010). STEM teachers in professional learning communities: A knowledge synthesis. National Commission on Teaching and America's Future.

Gamage, D., Perera, I., \& Fernando, S. (2016). Evaluating effectiveness of MOOCs using empirical tools: Learners' perspective. In The 10th International Technology, Education and Development Conference (pp. 8276-8284). Valencia, Spain 2016. https://doi.org/10.21125/inted.2016.0937

Gosselin, D. C., Thomas, J., Redmond, A., Larson-Miller, C., Yendra, S., Bonnstetter, R. J., \& Slater, T. F. (2010). Laboratory earth: A model of online K-12 teacher coursework. Journal of Geoscience Education, 58(4), 203-213. https://doi.org/10.5408/1.3534859

Guskey, T. R. (2002). Professional Development and Teacher Change. Teachers and Teaching, 8(3), 381-391. https://doi.org/10.1080/135406002100000512

Haney, J. J., Wang, J., Keil, C., \& Zoffel, J. (2007). Enhancing teachers' beliefs and practices through problem-based learning focused on pertinent issues of environmental health science. The Journal of Environmental Education, 38(4), 25-33. https://doi.org/10.3200/JOEE.38.4.25-33

Hankel, N. A. (2019). Evaluating a Science Professional Development for Elementary Teachers: Effects on Self-Efficacy and Perceptions of Classroom Practice (Doctoral dissertation, UCLA).

Harding, N. (2016). Improving Elementary School Teacher'Self-Efficacy towards Teaching Science. Social Science Review, 2(1), 51-67.

Kang, E. J., McCarthy, M. J., \& Donovan, C. (2019). Elementary teachers' enactment of the NGSS science and engineering practices. Journal of Science Teacher Education, 30(7), 788-814. https://doi.org/10.1080/1046560X.2019.1630794 
Kazempour, M., \& Amirshokoohi, A. (2013). Exploring Elementary Pre-Service Teachers' Experiences and Learning Outcomes in a Revised Inquiry-Based Science Lesson: An Action Research. Journal of Education and Learning, 2(2), 144-154. https://doi.org/10.5539/jel. $\mathrm{v} 2 \mathrm{n} 2 \mathrm{p} 144$

Koukis, N., \& Jimoyiannis, A. (2017). Designing MOOCs for teacher professional development: Analysis of participants' engagement. In A. Mesquita and P. Peres (Eds.), Proceedings of the 16th European Conference on e-Learning, ECEL 2017 (pp. 271-280). Porto: ACPI.

Koukis, N., \& Jimoyiannis, A. (2019). MOOCS for teacher professional development: exploring teachers' perceptions and achievements. Interactive Technology and Smart Education, 16(1), 74-91. https://doi.org/10.1108/ITSE-10-2018-0081

Kreischer-Gajewicz, G. M. (2019). Examination of the Change in Science Content Knowledge, Personal Science Teacher Efficacy, and Science Teaching Outcome Expectancy Due to Participation in Modeling Instruction Professional Development (Doctoral dissertation, Bowling Green State University).

Menon, D., \& Sadler, T. D. (2017). Preservice elementary teachers' science self-efficacy beliefs and science content knowledge. Journal of Science Teacher Education, 27(6), 649-673. https://doi.org/10.1007/s10972-016-9479-y

Mertasari, N. M. S., \& Candiasa, I. M. (2020). Improving self-efficacy in the teaching of prospective mathematics teachers by involving them in the online teacher community. In Journal of Physics: Conference Series, 1516(1), 012038. IOP Publishing. https://doi.org/10.1088/1742-6596/1516/1/012038

Mintzes, J. J., Marcum, B., Messerschmidt-Yates, C., \& Mark, A. (2013). Enhancing self-efficacy in elementary science teaching with professional learning communities. Journal of science teacher education, 24(7), 1201-1218. https://doi.org/10.1007/s10972-012-9320-1

Moreno-Marcos, P. M., Muñoz-Merino, P. J., Maldonado-Mahauad, J., Pérez-Sanagustín, M., Alario-Hoyos, C., \& Kloos, C. D. (2020). Temporal analysis for dropout prediction using self-regulated learning strategies in self-paced MOOCs. Computers \& Education, 145, 103728 .

Mulholland, J., Dorman, J. P., \& Odgers, B. M. (2004). Assessment of science teaching efficacy of preservice teachers in an Australian university. Journal of Science Teacher Education, 15(4), 313-331. https://doi.org/10.1023/B:JSTE.0000048334.44537.86

Oh, E. G., Chang, Y., \& Park, S. W. (2019). Design review of MOOCs: Application of e-learning design principles. Journal of Computing in Higher Education, 1-21. https://doi.org/10.1007/s12528-019-09243-w

Peters-Burton, E. E., Merz, S. A., Ramirez, E. M., \& Saroughi, M. (2015). The effect of cognitive apprenticeship-based professional development on teacher self-efficacy of science teaching, motivation, knowledge calibration, and perceptions of inquiry-based teaching. Journal of Science Teacher Education, 26(6), 525-548. 
https://doi.org/10.1007/s10972-015-9436-1

Qian, Y., Hambrusch, S., Yadav, A., \& Gretter, S. (2018). Who needs what: Recommendations for designing effective online professional development for computer science teachers. Journal of Research on Technology in Education, 50(2), 164-181. https://doi.org/10.1080/15391523.2018.1433565

Ravandpour, A. (2019). The relationship between EFL teachers' continuing professional development and their self-efficacy: A structural equation modeling approach. Cogent Psychology, 6(1). https://doi.org/10.1080/23311908.2019.1568068

Riggs, I. M., \& Enochs, L. G. (1990). Toward the Development of an Elementary Teacher's Science Teaching Efficacy Belief Instrument. Science Education, 74(6), 625-637. https://doi.org/10.1002/sce.3730740605

Savran, A., \& Çakiroğlu, J. (2001). Preserve biology teachers' perceived efficacy beliefs in teaching biology. Hacettepe Üniversitesi Eğitim Fakültesi Dergisi, 21(21). https://dergipark.org.tr/tr/pub/hunefd/issue/7817/102684

Schneider, S. M. (2020). Professional learning communities on phenomenon-based science pedagogy: Contrastive cases of urban elementary teachers (Graduate Theses and Dissertations. 17982). Retrieved from https://lib.dr.iastate.edu/etd/17982

Tzovla, E., \& Kedraka, K. (2020a). Teaching Biology in Primary Education. International Journal of Educational Technology and Learning, 8(2), 91-97. https://doi.org/10.20448/2003.82.91.97

Tzovla, E. \& Kedraka, K. (2020b). Personal biology teaching efficacy beliefs and biology teaching outcome expectancy of in-service elementary teachers. European Journal of Education Studies, 7(10), 143-159. https://doi.org/10.46827/ejes.v7i10.3286 ISSN 2501 1111.

Tzovla, E., Kedraka, K., \& Kaltsidis, C. (2021a). Investigating In-service Elementary School Teachers' Satisfaction with Participating in MOOC for Teaching Biological Concepts. Eurasia Journal of Mathematics, Science and Technology Education, 17(3), em1946. https://doi.org/10.29333/ejmste/9729

Tzovla, E., Kedraka, K., Karalis, T., Kougiourouki, M, \& Lavidas, K. (2021b). Effectiveness of in-service elementary school teacher professional development MOOC: experimental research. Contemporary Educational Technology 13(4) ep324. https://doi.org/10.30935/cedtech/11144

Velthuis, C., Fisser, P., \& Pieters, J. (2014). Teacher training and pre-service primary teachers' self-efficacy for science teaching. Journal of Science Teacher Education, 25(4), 445-464. https://doi.org/10.1007/s10972-013-9363-y

Yoo, J. H. (2016). The effect of professional development on teacher efficacy and teachers' self-analysis of their efficacy change. Journal of Teacher Education for Sustainability, 18(1), 84-94. https://doi.org/10.1515/jtes-2016-0007 


\section{Macrothink}

\section{Appendix}

\section{Bio-STEBI-A instrument}

\section{PBTE statements}

2. I am continually finding more effective ways to teach biological concepts.

3*. Even when I try very hard, I don't teach biological concepts as effective as I do in most subjects

5. I know to teach biological concepts effectively

6*. I am not very effective in monitoring biological concepts experiments.

8*. I generally teach biological concepts ineffectively.

12. I understand biological concepts well enough to be effective in teaching elementary science.

$17^{*}$. I find it difficult to explain to students how biological concepts experiments work.

18. I am typically able to answer students' biological concepts questions.

$19 *$ I wonder if I have the necessary skills to teach biological concepts.

$21 *$. Given a choice, I would not invite the principal to evaluate my biological concepts teaching.

22*. When a student has difficulty understanding biological concepts, I am usually at a loss on how to help the student understand them better.

23. When teaching biological concepts, I usually welcome student questions.

$24 *$ I don't know what to do to turn students on to biological concepts.

\section{BTOE statements}

1. When a student does better than usual in biological concepts, it is because the teacher exerted an extra effort.

4. When the biological concepts grades of students improve, it is most often due to their teacher has found a more effective teaching approach.

7. If students are underachieving in biological concepts, it is most likely due to ineffective science teaching. 


\section{Macrothink \\ International Journal of Learning and Development \\ ISSN 2164-4063 \\ 2021, Vol. 11, No. 3}

9. The inadequacy of student's biological concepts background can be overcome by effective teaching.

$10^{*}$. Teachers are not to blame for the low performance of some students in biological concepts.

11. When a low achieving child progresses in biological concepts, it is usually due to the extra attention given by the teacher.

13*. Increased effort in biological concepts teaching produces little change in some students' science achievement.

14. The teacher is generally responsible for the achievement of students in biological concepts.

15. Students' achievement in biological concepts is directly related to their teacher's effectiveness in biological concepts teaching.

16. If parents comment that their child is showing more interest in biological concepts at school, it is probably due to the performance of the child's teacher.

$20 *$. Effectiveness in teaching biological concepts does not greatly affect the performance of low-motivation students.

$25^{*}$. No matter how well the teacher teaches the biological concepts, he/she cannot help some children to understand the biological concepts in depth.

\section{Copyright Disclaimer}

Copyright for this article is retained by the author(s), with first publication rights granted to the journal.

This is an open-access article distributed under the terms and conditions of the Creative Commons Attribution license (http://creativecommons.org/licenses/by/4.0/). 